\title{
Two Dimensional NMR and NMR Relaxation Studies of Coal Structure
}

\section{DISCLAIMER}

This report was prepared as an account of work sponsored by an agency of the United States Government. Neither the United States Government nor any agency thereof, nor any of their employees, makes any warranty, express or implied, or assumes any legal liability or responsibility for the accuracy, completeness, or usefulness of any information, apparatus, product, or process disclosed, or represents that its use would not infringe privately owned rights. Reference herein to any specific commercial product, process, or service by trade name, trademark, manufacturer, or otherwise does not necessarily constitute or imply its endorsement, recommendation, or favoring by the United States Government or any agency thereof. The views and opinions of authors expressed herein do not necessarily state or reflect those of the United States Government or any agency thereof.

\section{FINAL REPORT}

performance period September 13, 1994 to January 31, 1995

Kurt W. Zilm

Department of Chemistry

Yale University

New Haven, CT 06511

Prepared for the Department of Energy

Agreement No. DE-FG22-91PC91285

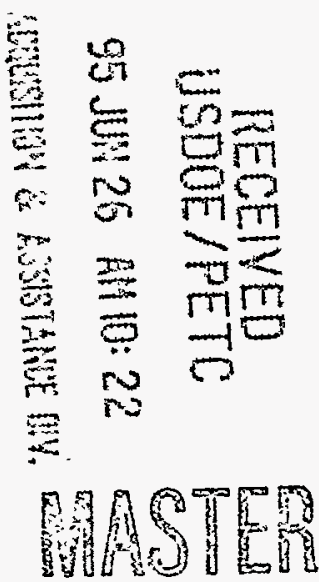


This report was prepared as an account of work sponsored by the United States Government. Neither the United States nor the Department of Energy, nor any of their employees, nor any of their contractors, subcontractors, or their employees, make any warranty, express or implied, or assumes any legal liability or responsibility for the accuracy, completeness, or usefulness of any information, apparatus, product or process disclosed or represents that its use would not infringe on privately-owned rights.

US/DOE Patent Clearance is not required prior to publication of this document. 


\section{Project Summary}

The research program in this grant focused on developing new solids NMR techniques for improved NMR analysis of coal structure. Our goal has been to provide accurate average model coal structures to guide development of coal beneficiation chemistry.

Four major areas of inquiry have been pursued in this grant. Advanced solid state NMR methods were developed to assay the distribution of the various important functional groups that determine the reactivity of coals. Special attention was paid to methods that are compatible with the very high magic angle sample spinning rates needed for operation at the high magnetic field strengths available today. Polarization inversion methods utilizing the difference in heat capacities of small groups of spins were particularly effective. Methods combining proton-proton spin diffusion with ${ }^{13} \mathrm{C}$ CPMAS readout were investigated as a means of determining the connectivity of functional groups in coals in a high sensitivity relay type of experiment. Additional work was aimed at delineating the role of methyl group rotation in the proton NMR relaxation behavior of coals.

Most of our work was in the further development of spectral editing NMR methods for solids. One of our greatest successes is a new class of spectral editing methods for separating different types of carbon functional groups in ${ }^{13} \mathrm{C}$ CPMAS spectra. In the past, NMR spectroscopists have relied upon the dipolar couplings to attached protons to separate ${ }^{13} \mathrm{C}$ signals coming from $\mathrm{C}, \mathrm{CH}, \mathrm{CH}_{2}$ and $\mathrm{CH}_{3}$ groups. Such methods assume that molecular motion is severely limited so that the ${ }^{13} \mathrm{C}-{ }^{1} \mathrm{H}$ dipolar couplings have characteristic strengths. We have developed a new set of methods that utilize the polarization inversion process, and rely upon the relative heat capacities (in the NMR sense) of the ${ }^{13} \mathrm{C}$ nuclei and their directly attached protons. In this manner 
$\mathrm{CH}_{3}, \mathrm{CH}_{2}, \mathrm{CH}$ and $\mathrm{C}$ groups can be readily distinguished even if there is a wide distribution in molecular mobility. By taking linear combinations of a few different spectra we can generate subspectra which contain just one type of carbon. We find the new methods are simple to employ and require what we consider to be fairly standard solids NMR hardware.

These techniques have been applied in a comprehensive study of the Argonne Premium coals. Several generalizations are apparent from these new data. First, the subspectra show there are many more methyl groups in coals of all ranks than is generally believed. In addition, a significant number of aliphatic $\mathrm{CH}$ groups are found, and these account for the majority of the $40-60$ ppm shoulder in the aliphatic region of the ${ }^{13} \mathrm{C}$ CPMAS NMR spectra of mid-rank coals. Interestingly, the $\mathrm{CH}$ subspectra for coals of different ranks show significant trends. Low rank coals are found to have few aliphatic $\mathrm{CH}$ groups. These grow in with increasing rank, maximizing at intermediate rank parameters. Further maturation leads to a progressive decrease in aliphatic $\mathrm{CH}$ carbon centers, and they disappear altogether at high ranks. The subspectra also demonstrate the near complete absence of $\mathrm{CH}_{2}$ or $\mathrm{CH}_{3}$ groups attached to $\mathrm{O}$ or other heteroatoms (except in lower rank coals). Furthermore, the oft invoked $\mathrm{CH}_{2}$ aryl-aryl bridges are rarely found.

With a fairly quantitative breakdown of the ${ }^{13} \mathrm{C}$ CPMAS spectra into the four carbon types in both the aliphatic and aromatic region, we can place some severe restrictions on sensible average structures. These data can also be compared to ultimate analysis data, and the agreement between the H/C ratios determined by analysis and these new NMR methods is quite good. In the case of the Pocahontas coal, the NMR experiments were used to determine the structural parameters Stock and co-workers determined via a combination of solids NMR and chemical degradation. The new methods developed in our lab give similar results, but are inherently more reliable. 
This work has resulted in a number of papers on the development of spectral editing methods and the associated spin dynamics. Further work is being carried out to carefully assess the quantitative aspects of the methods. While the techniques work well on the NMR hardware developed in our laboratory, many commercial instruments do not have the same level of stability and RF excitation purity as those we have constructed at Yale. As such we are developing protocols that will ameliorate the most common performance deficiencies of commercial NMR instruments in applications of our new methods. Although we have completed what we consider to be a seminal paper on the spectral editing results we have obtained on the Argonne Coal samples, we are delaying its publication until we are certain that we have determined how other researchers may reproduce our data on less capable instrumentation. We feel this is important for building confidence in our methods with the rest of the fossil fuel community that employs solids NMR in their research.

\section{Project Output:}

\section{Publications:}

Wu, X.; Zilm, K. W. "Heterogeneity of Cross Relaxation in Solid State NMR" J. Magn. Reson. 93, 265-278 (1991).

Jolanta M. Snowel "NMR Investigations and Dynamic Properties of Coals and Matrix-Isolated Phosphorus and Alkali Metal Clusters", Ph.D. thesis, Yale University, (1993).

Xiaoling Wu and Kurt W. Zilm, "Methylene-only Subspectrum in CPMAS NMR" J. Magn. Reson. A 104, (1993). Also related posters at the 33rd and 34th Experimental NMR Conf., $(1992,1993)$.

Wu, X.; Zilm, K. W., "Complete Spectral Editing in CP/MAS NMR" J. Magn. Reson. A 102, 205-213 (1993).

Wu, X.; Zilm, K. W., "Cross Polarization with High Speed Magic Angle Spinning" J. Magn. Reson. A. 104, 119 (1993). 
Han, O. H.; Lin, C. H.; Sustache, N.; McMillan, M.; Carruthers, D.; Zilm, K. W.; Haller, G. L. "Solid State NMR Spectroscopic Investigation on Hydrotreating Catalyst and Related Materials" Appl. Catal. A 98, 195-210, (1993).

Augustine, M. P.; Zilm, K. W.; Zax, D. B., "Field Dependent Isotropic Shifts in Solid State NMR: A Floquet Treatment" J. Chem. Phys. 98, 9432-9443, (1993).

Wu, X.; Zilm, K. W. "Methylene-only Subspectrum in CPMAS NMR" J. Magn. Reson. A 104, 119-122 (1993).

Han, O. H.; Larsen, G.; Zilm, K. W.; Haller, G. L. "Methoxy formation/spillover on $\mathrm{Pd} / \mathrm{Al}_{2} \mathrm{O}_{3}$ studied by 13C, 1H NMR" in New Aspects of Spillover Effect in Catalysis, Elsevier Science Pub., pg. 223-228 (1993).

Wu, X.; Burns, S. T.; Zilm, K. W. "Spectral Editing in CPMAS NMR. Generating Subspectra Based on Proton Multiplicities" J. Mag. Reson. A 111, 29-36 (1994).

Zilm, K.W. "Spectral Editing in C-13 Spectra of Hydrocarbon Solids" Encyclopedia of Magnetic Resonance, (1995).

Invited Talks:

"CPMAS Spectral Editing" presented at the University of Illinois at Chicago, Nov., 1993

"Complete Spectral Editing in CPMAS Spectroscopy" presented at the $34^{\text {th }}$ Experimental NMR conference, Asilomar CA, March, 1994.

"Spectral Editing in Solids: Applications to Organic Geochemistry", presented at Exxon Engineering and Research Corp., May, 1994.

"Solid State NMR and Spectral Editing: Applications to Geochemical Problems", presented at the 1994 Eastern Analytical Symposium, Somerset NJ, Nov. 1994

"Spectrum Editing in CPMAS NMR Using Polarization Inversion" Rocky Mtn. Conf., Denver, Aug. (1993)

Other Invited talks by K. W. Zilm: Dahhousie Univ., Nov. (1991); FSU, Feb. (1992); Univ. of Florida, Apr. (1992); UC Berkeley, Sept. (1992); Columbia Univ., Feb. (1993), U. Ill. at Chicago (1993), ENC(1994), March Natl. APS (1992, 1994) 
Graduates Students:

Jolanta Snowel

Jiangming Zhang

Anil Mehta

Sean Burns

Matthew Augustine

I-Wen Wu

Kristen Kumashiro

Post-doctoral Associates

Oc Hee Hahn

Xiaoling Wu current position

NRC post-doctoral associate

engineer for IBM, Fishkill, NY

3 rd year graduate student

3 rd year graduate student

NSF postdoctoral fellow

5 th year graduate student

5 th year graduate student

current position

scientist, Korean Basic Research Institute

staff scientist, Yale University 